\title{
Multidecadal Variability of the Summer Length in Europe*
}

ARTICLE in JOURNAL OF CLIMATE·APRIL 2015

Impact Factor: 4.9 · DOI: 10.1175/JCLI-D-14-00429.1

DOWNLOADS

8
VIEWS

51

3 AUTHORS, INCLUDING:

\section{David Barriopedro}

Complutense University of Madrid 37 PUBLICATIONS 869 CITATIONS SEE PROFILE
Ricardo García-Herrera

Complutense University of Madrid 197 PUBLICATIONS 2,536 CITATIONS

SEE PROFILE 


\title{
Multidecadal Variability of the Summer Length in Europe*
}

\author{
CRISTINA PEÑA-ORTIZ \\ Departamento de Sistemas Físicos, Químicos y Naturales, Facultad de Ciencias Experimentales, Universidad \\ Pablo de Olavide, Seville, Spain \\ DAVID BARRIOPEDRO AND RICARDO GARCÍA-HERRERA \\ Departamento de Fisica de la Tierra II, Facultad de Ciencias Físicas, Universidad Complutense de Madrid, and \\ IGEO, Instituto de Geociencias (CSIC-Universidad Complutense de Madrid), Madrid, Spain
}

(Manuscript received 17 June 2014, in final form 30 March 2015)

\begin{abstract}
This study analyzes the multidecadal variability of the European summer timing and length. The dates of the summer onset and end are computed through an objective algorithm based on locally defined temperature thresholds applied to the European daily high-resolution gridded dataset (E-OBS) during the period 1950-2012. The results reveal a European mean summer lengthening of 2.4 days decade $^{-1}$ for the period 1950-2012. However, this trend is confined to the post-1979 period, when lengthening rates range between 5 and 12 days decade $^{-1}$ over western Europe and the Mediterranean region. In contrast, a widespread summer shortening occurred for the 1950-78 period. The reported changes in the summer length are in agreement with temperature trends during June and September, which affect the summer onset and end dates.

It is shown that the shortening and lengthening with a turning point around 1979 is a leading mode of the summer length multidecadal variability. The trends in the summer length can be explained by the superposition of an Atlantic multidecadal oscillation signal and a long-term trend toward more persistent summers in Europe associated with global warming.
\end{abstract}

\section{Introduction}

European average temperatures have risen over the last century, with a faster rate over the last decades that ranges between $0.2^{\circ}$ and $0.5^{\circ} \mathrm{Cdecade}^{-1}$ for the period 1981-2012 (Hartmann et al. 2013). The annual cycle of the surface temperature over Europe has also experienced changes over the last decades, including a shift toward earlier seasons and larger annual peak-to-peak amplitudes, the latter being opposite to overall trends over land (e.g., Stine et al. 2009). Many indicators of seasonality changes are based on temperature-related impacts on ecosystems, and hence they provide estimates

\footnotetext{
* Supplemental information related to this paper is available at the Journals Online website: http://dx.doi.org/10.1175/JCLI-D-1400429.s1.

Corresponding author address: Cristina Peña-Ortiz, Dpto. Sistemas Físicos, Químicos y Naturales, Universidad Pablo de Olavide, Ctra. de Utrera, Km. 1, 41013 Sevilla, Spain.

E-mail: cpenort@upo.es
}

of changes in the seasonal timing of the growing season. For example, an earlier spring onset has been reported over certain regions of the Northern Hemisphere based on phenological changes in various plant species and forestry (Cayan et al. 2001; Sparks and Menzel 2002; Matsumoto et al. 2003; Chmielewski et al. 2004) or on the return dates of migrant birds (Cotton 2003). Schwartz et al. (2006) found that spring first leafing and first flowering have advanced on average by 1.2 and 1.0 days decade ${ }^{-1}$ respectively in the period 1955-2002 across the Northern Hemisphere. Similarly, Menzel et al. (2006) showed that the flowering and fruiting dates of both spring and summer species in Europe advanced 2.5 days decade ${ }^{-1}$ over the period 1971-2000.

Temperature indices have also been used as indicators of changes in the seasonal cycle (e.g., Stine et al. 2009, and references therein) and in the timing of specific seasons. Christidis et al. (2007) used observational daily temperature data over the period 1950-99 to determine the global and regional mean length of the growing season by defining the onset (end) as the date when the annual mean temperature at each grid point averaged 
over the analyzed period crossed the smoothed seasonal cycle of each year for the first (second) time. They reported an European mean lengthening of the growing season of 2.1 days decade ${ }^{-1}$ over 1950-99 because of an advance of the spring onset of 1.7 days decade ${ }^{-1}$ and a delay of the autumn onset of 0.4 days decade ${ }^{-1}$.

The assessment of the summer onset and length variability is of utmost importance. Thus, in recent years, European summer high-impact weather has been in the spotlight for several studies because it may be becoming more severe. The Fifth Assessment Report of the IPCC (Hartmann et al. 2013) states that it is likely that the frequency of heat waves has increased in large parts of Europe. Della-Marta et al. (2007a) reported that the length of summer heat waves over western Europe has doubled and the frequency of hot days has almost tripled over the period 1880-2005. Furthermore, Barriopedro et al. (2011) showed that the probability of a summer experiencing mega heat waves will increase significantly within the next decades over Europe. Regional model simulations based on different scenarios of climate change project an increasing frequency of heat waves in Europe during the twenty-first century (Christensen et al. 2013). Although changes in temperature variability play an important role in the characteristics of European heat waves, the projected trends in frequency are roughly attributed to changes in the mean temperature (e.g., Barriopedro et al. 2011). The severity of extreme summer episodes may have dramatic effects on population health and mortality (e.g., Robine et al. 2008). This is evidenced in D'Ippoliti et al. (2010), who evaluated the effects of European heat waves that occurred between 1990 and 2004 and estimated rates of mortality between $7.6 \%$ and $33.6 \%$. In addition, there is a "harvesting" effect, whereby the highest mortality rate is associated with the earliest heat wave within a given season (García-Herrera et al. 2010). Thus, changes in the summer length could also affect the seasonal timing of heat wave occurrence.

In recent years several studies have explored the mechanisms that may have contributed to the increasing severity of summer weather. In addition to a warming long-term trend, multidecadal variations of the European summer climate have been reported (e.g., Sutton and Hodson 2005) and linked to a spatially coherent mode of variability in North Atlantic sea surface temperatures (SSTs), often referred to as the Atlantic multidecadal oscillation (AMO; Enfield et al. 2001). Persistent positive phases of the AMO, corresponding to warm North Atlantic SSTs, occurred during the pre-1900, 1930s-1950s, and 1990s-present periods and were associated with relatively warm temperatures over large parts of Europe. Sutton and Hodson (2005) reported a European mean warming of $0.25^{\circ}-0.75^{\circ} \mathrm{C}$ during the positive phase of the AMO. Other studies have also reported some influence of the AMO on the decadal variability of European summer heat waves (e.g., Della-Marta et al. 2007b). Therefore, the summer length could also exhibit multidecadal changes associated with the AMO.

Studies addressing changes in the summer length within Europe have mainly focused on relatively small areas, by using either fixed (e.g., Kirbyshire and Bigg 2010) or point-dependent (e.g., López de la Franca et al. 2013) temperature thresholds. The reasons for this relatively low number of studies may lie in the intrinsic difficulty to define the summer onset, since its arrival is generally a continuation of spring events, as stated by Kirbyshire and Bigg (2010). These authors looked into the timing of the British summer using a temperature threshold of $14^{\circ} \mathrm{C}$ and found a summer advance of 3 days decade $^{-1}$ over the period 1954-2000. On the other hand, at larger (continental) scales, Klein Tank and Können (2003) evaluated the number of summer days with maximum temperature above $25^{\circ} \mathrm{C}$ using daily series of temperature observations from more than 100 meteorological stations in Europe. They found an increasing average trend of 0.8 summer days per decade over the period 1946-99, with higher values over some regions of southern and central Europe, where it ranged between 4 and 6 days decade ${ }^{-1}$. While this approach could be employed as an approximate metric of the summer length, it should be stressed that the use of spatially fixed temperature thresholds could bias the determination of the summer onset and end over areas with large climatological temperature gradients like Europe. Thus, although a threshold of $25^{\circ} \mathrm{C}$ could be representative of summer temperatures for central and southern regions of Europe, this could be too warm to define a realistic summer length in northernmost Europe. To the best of our knowledge, no systematic attempt has been made to characterize multidecadal changes in the onset, end and length of the European summer. Thus, in this study we use an objective algorithm to determine the local length of the summer over Europe over the period 1950-2012 (section 2). In addition, we explore long-term trends in the summer onset, end, and length as well as their multidecadal changes over the 63-yr period (section 3). The results are also discussed in the context of global warming and natural (AMO-related) multidecadal variability. Finally, the main conclusions are summarized in section 4 .

\section{Data and methodology}

We use daily mean data from the European daily high-resolution gridded dataset (E-OBS), version 9 (v9) 

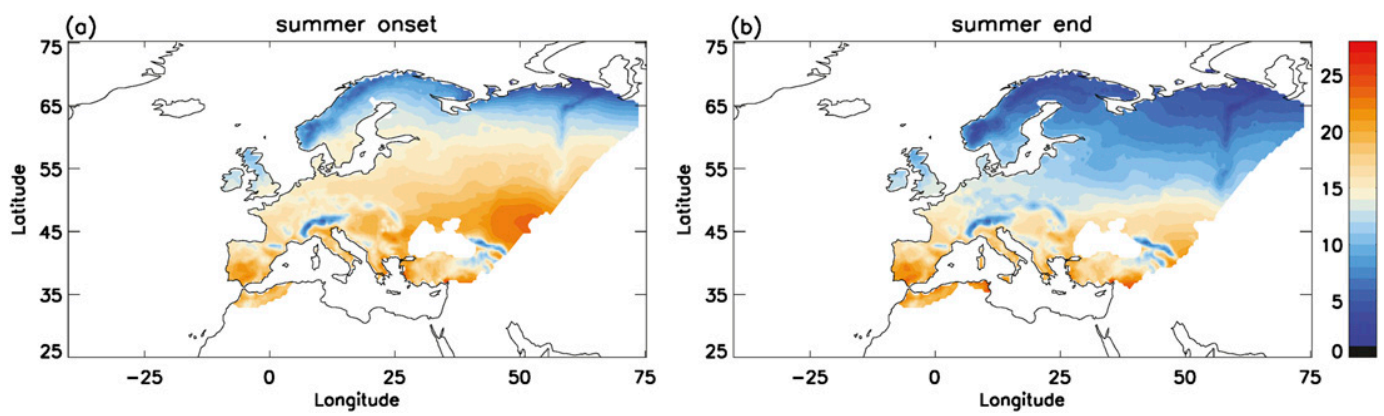

FIG. 1. Spatial distribution of the local temperature threshold $\left({ }^{\circ} \mathrm{C}\right)$ : (a) $T_{\text {on }}$ and (b) $T_{\text {end }}$, used to define the summer onset and end, respectively.

(Haylock et al. 2008), covering the period 1950-2012. This dataset includes several variables (mean, maximum and minimum temperature, precipitation, and sea level pressure) on a daily basis since 1950 and for the European area $25^{\circ}-75^{\circ} \mathrm{N}, 40^{\circ} \mathrm{W}-75^{\circ} \mathrm{E}$. The data are provided on two different spatial resolutions and on two different grids, the one used here being a regular grid of $0.5^{\circ} \times$ $0.5^{\circ}$ in longitude/latitude. The E-OBS dataset represents the most comprehensive high-resolution European dataset based on a large number of observations from European weather stations on land. It is obtained through interpolation of station-blended data of varying length from the European Climate Assessment and Dataset (ECA\&D). This dataset has proven reliable, although it may display biases in areas where relatively few stations are available (e.g., Kyselý and Plavcová 2010). Overall, errors in daily mean temperature tend to be lower than in precipitation, and the mean in the E-OBS dataset compares better with existing datasets than do the tails of the distributions. Still, there are inhomogeneities in the gridded data, which are mainly related to inhomogeneities in the underlying stations (Hofstra et al. 2009).

To test whether the conclusions of this paper are robust with respect to the data employed and the spatial resolution, we have repeated all the analyses for the 1958-2012 period using two additional datasets: 1) the 2-m daily temperature of the NCEP-NCAR reanalysis (NNR) in a spectral T62 resolution Gaussian grid with $192 \times 94$ points (Kalnay et al. 1996) and 2) the Hadley Centre Global Historical Climatology Network-Daily (HadGHCND) dataset (Caesar et al. 2006), which provides station-based daily mean temperature observations on a coarse grid $\left(3.75^{\circ} \times 2.75^{\circ}\right.$ longitude/latitude $)$. Note that the underlying data, quality tests, and spatial resolution differ with respect to those of the E-OBS dataset. Although the datasets are not fully independent, the results based on the E-OBS grid are consistent with those found with the other datasets. Therefore, we will only show the results obtained with the E-OBS dataset and stress the differences with the other data products when required. Some of the results for the other datasets can be found in the supplementary material.

In meteorological terms the Northern Hemisphere summer is usually defined as the period from June to August. Thus, in order to compute the summer onset date for each year at local scale (i.e., the calendar day corresponding to the beginning of the summer) we have used a criterion based on the monthly mean temperature of June. First, the local temperature time series for each calendar day have been detrended and the average climatological temperature between 1 and 30 June $\left(T_{\text {on }}\right)$ over the period 1950-2012 has been computed for each grid point. The value $T_{\text {on }}$ has been used as the temperature threshold for the identification of the summer onset date, as explained below. On the other hand, to define the summer end we have used the long-term average of the detrended temperature series between 1 and 30 September $\left(T_{\text {end }}\right)$. This period corresponds to the first month of the boreal autumn in meteorological terms, and hence the summer end is identified with the autumn onset. Figure 1 represents the spatial distribution of $T_{\text {on }}$ and $T_{\text {end }}$ over Europe. The values of $T_{\text {on }}$ and $T_{\text {end }}$ decrease with latitude and are similar in southern Europe, where they reach $25^{\circ} \mathrm{C}$, although they are below $15^{\circ} \mathrm{C}$ over mountain regions. Conversely, over northern Europe $T_{\text {end }}$ varies from $5^{\circ}$ to $15^{\circ} \mathrm{C}$ and it is lower than $T_{\text {on }}\left(10^{\circ}-17^{\circ} \mathrm{C}\right)$, because of the rapid cooling of northern regions during September (not shown).

Once we have defined the local thresholds, a 30-day moving average was computed from the nondetrended time series from April to December for each year and grid point. We then chose the first 30-day mean period whose temperature was above (below) $T_{\text {on }}\left(T_{\text {end }}\right)$ and defined the onset (end) date of the summer as the first day of the so-detected 30-day period. Consequently, the summer length is defined as the difference (in days) 
between the start and end dates. To obtain estimates of the mean summer onset, end, and length for the entire continent we applied the same algorithm (including the detection of thresholds $T_{\text {on }}$ and $T_{\text {end }}$ ) to the European mean temperature series. The daily mean temperature in Europe was computed by averaging data from all the grid points (weighted by the cosine of the latitude).

Results shown below are robust against the methods used to compute the summer onset and end. To check this, we applied 10-day moving averages and set the summer onset (end) on those days whose mean temperature was above (below) the long-term average of the detrended 10-day mean temperature centered on the summer solstice (autumn equinox) in the Northern Hemisphere or, in a different attempt, around the beginning of June (September). These approaches gave results consistent with the findings described in the following sections; however, they involved the selection of a 10-day period as the reference date for the climatological summer onset and/or end, which is somewhat arbitrary.

Finally, we have used the monthly time series of the AMO provided by the NOAA (http://www.esrl.noaa. gov/psd/data/timeseries/AMO/) to explore its influence on the multidecadal variability of the summer onset, end, and length. The AMO is defined as the detrended series of the area-weighted average of monthly Kaplan SSTs (on a $5^{\circ} \times 5^{\circ}$ regular grid) over the North Atlantic basin (about $0^{\circ}-70^{\circ} \mathrm{N}$ ), as described in Enfield et al. (2001). In addition, to quantify the effect of global warming on the trends in the summer onset, end, and length, and to compare it with that of natural factors operating at multidecadal time scales such as the AMO, we have also employed the 1950-2012 time series of the global mean temperature (HadCRUT3v_GL) provided by the University of East Anglia Climate Research Unit (CRU; http://www.cru.uea.ac.uk/cru/data/ temperature/). This time series is based on combined land (CRUTEM3) and marine (SSTs from HadSST2) temperature anomalies on a $5^{\circ} \times 5^{\circ}$ grid.

For the different trend analyses of the summer length and timing performed in the following sections, we have computed a linear regression over the period 1950-2012. The $95 \%$ confidence interval is defined as the two-sigma uncertainty of the slope parameter. We have also carried out several correlation analyses (through the Pearson correlation coefficient) by using the original and 10-yr smoothed time series. In both cases, we take into account the reduction in degrees of freedom due to time series autocorrelation, following Oort and Yienger (1996). The significance level is fixed at $p<0.05$ for a two-tailed Student's $t$ test.

\section{Results}

\section{a. Changes in summer length and timing}

Figures 2a-c depict the climatological mean (19502012) date of the summer onset and end as well as the climatological mean summer length over Europe, while Figs. 2d-f display the European time series of the summer onset, end, and length, respectively (gray line). Figure $2 \mathrm{~b}$ shows that the summer starts between 16 and 26 May in southern and western Europe and between 26 May and 7 June in eastern and northern Europe. On the other hand, the European summer end (Fig. 2c) ranges between 26 August and 5 September. Thus, in spite of using a local criterion, there are spatial differences in the dates of the summer onset and end that can be above 20 and 11 days, respectively. The summer length ranges between 80 and 110 days across Europe, with a rather uniform spatial distribution, showing minima in some parts of Scandinavia and the Black Sea region. Overall, the spatial distributions of the summer onset, end, and length display a smooth transition across Europe, although there are also abrupt changes at regional scales. Most of them are located in coastal or high-altitude regions such as the Alps, where the seasonal cycle is substantially different from that of the surrounding regions. However, in eastern Turkey the duration of the summer is longer than in nearby regions, and Romania displays less persisting summers than adjacent countries. Interestingly, the former region coincides with an area where the spatial density of underlying stations in the E-OBS dataset is relatively low. Moreover, the signature over Romania is well confined to the national boundaries of this country. This suggests that the gridded data may suffer from systematic biases or temporal inhomogeneities therein. To test this hypothesis, we have repeated the analyses using the NNR and HadGHCND datasets (see Figs. S1 and S2 in the supplementary material). Overall, the results are in good agreement with those of the E-OBS dataset, but the regional signatures over Romania and eastern Turkey are much weaker, thus calling for caution regarding data quality and the results found for these regions.

Next, we focus on the analysis of the multidecadal variability of the summer timing. Figure 3 a shows the climatological trends of the summer length at local scales. There is a summer lengthening across extended areas of Europe that reaches significant values between 2 and 6 days decade $^{-1}$ for the period 1950-2012 and a continental-wide trend of 2.4 days decade $^{-1}$ (see the European trends in the summer length and timing in Table 1). This spatial pattern is consistent with the trends detected in the summer onset (Fig. 3d) and end (Fig. 3g), which show a generalized advance of the onset, 
(a) summer length

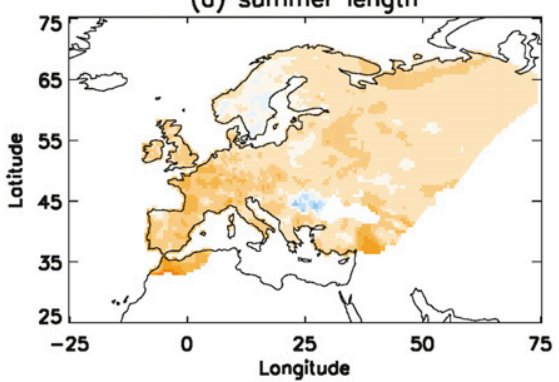

(b) summer onset

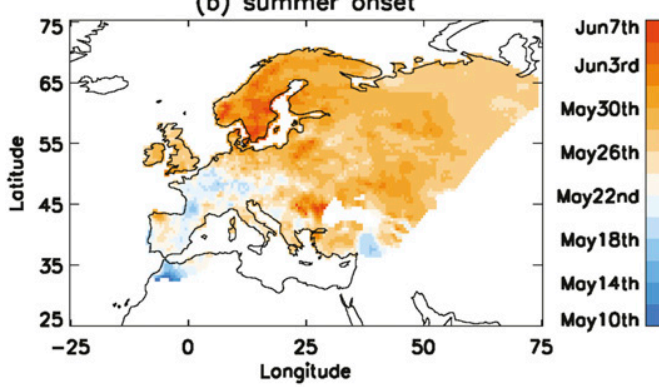

(c) summer end

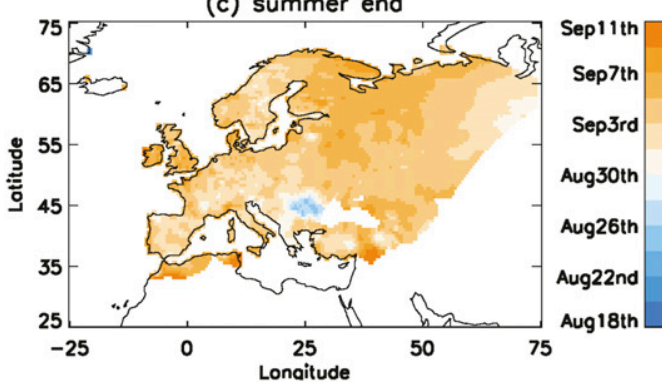

(d)

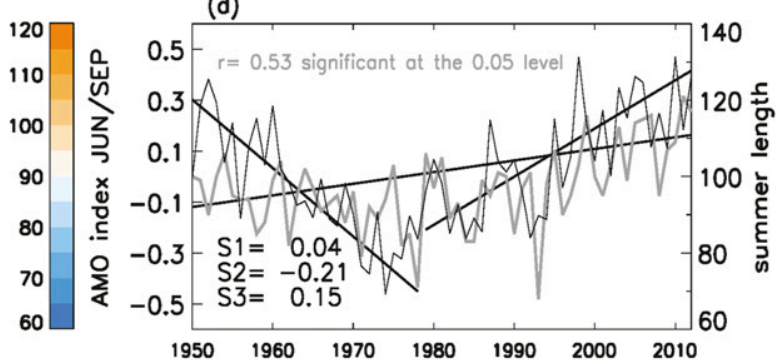

(e)


FIG. 2. Climatological (1950-2012) mean (a) summer length (days), (b) summer onset (day of the calendar year), and (c) summer end (day of the calendar year), and time series of the (d) June and September mean AMO index (black) and European summer length (days; gray), (e) June AMO index (black) and European summer onset dates (day of the calendar year; gray), and (f) September AMO index (black) and European summer end dates (day of the calendar year; gray). AMO index units are standard deviations (SD). Note that (d)-(f) show the linear regression of the AMO index, the slope parameters for 1950-2012 (S1), 1950-78 (S2), and 1979-2012 (S3), and the Pearson correlation coefficient between the AMO index and the summer length, onset, and end for (d)-(f), respectively. The slope parameters $\left(\mathrm{SD}\right.$ decade $^{-1}$ ) are statistically significant at the $95 \%$ confidence level.

more acute in western continental Europe and northern Russia, and a delayed end, mainly in eastern Europe and western Russia. We note that there are very large trends over the same regions that displayed suspicious climatological values of the summer length in Fig. 2a (i.e., Romania and eastern Turkey). For the HadGHCND and NNR datasets, the magnitude of the trends in these regions is lower and similar to that observed in surrounding areas. This again suggests data quality issues in the E-OBS grid over these regions, most likely involving the presence of temporal inhomogeneities (e.g., Hofstra et al. 2009). In spite of this, the results obtained for the HadGHCND and NNR datasets still display significant trends over these regions, and with the same sign as in the E-OBS dataset (Figs. S3 and S4 in the supplementary material). In addition, the continental estimates of the summer length and its trend are very close in the three data products analyzed herein. Therefore, potential local errors in the E-OBS dataset do not affect the main results regarding the spatial distribution of significant trends and their sign, as well as the quantitative estimates at continental scales. In fact, similar European trends are obtained after removing from the E-OBS grid those regions that display large discrepancies with respect to the other datasets (not shown).

The inspection of the temporal series of the summer length for the entire continent (Fig. 2d) reveals substantial multidecadal changes, with a trend toward less 
(o) length-1950-2012

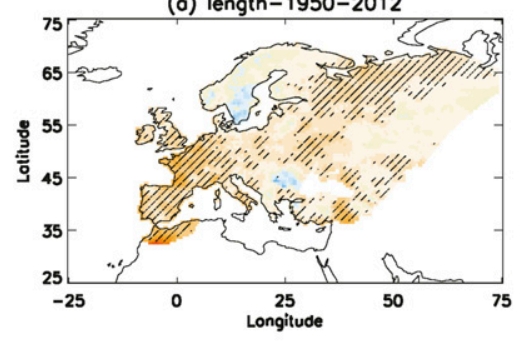

(d) onset-1950-2012

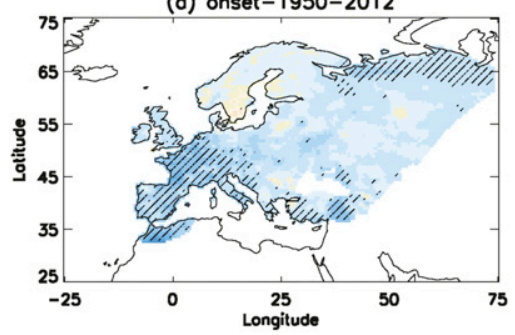

(g) end-1950-2012



(b) length-1950-1978

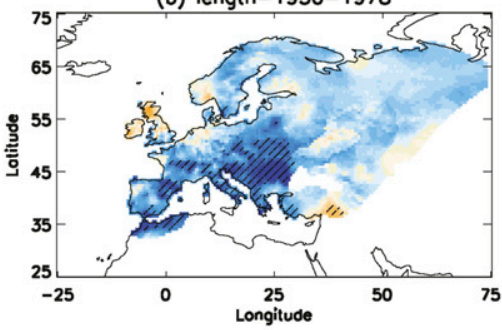

(e) onset-1950-1978

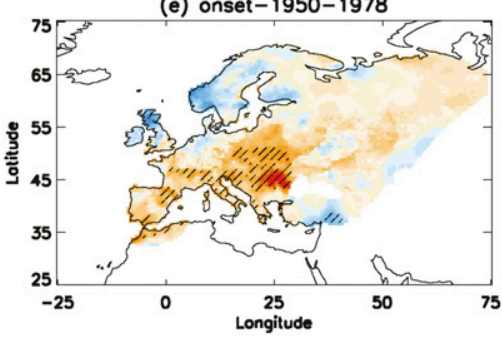

(h) end-1950-1978

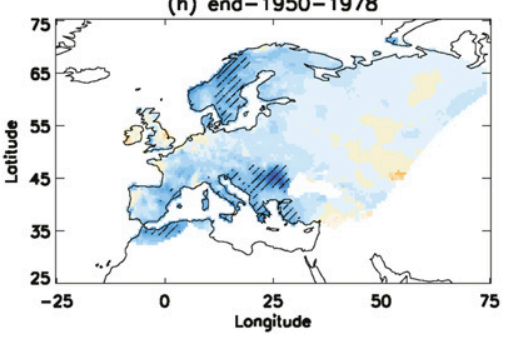

(c) length-1979-2012

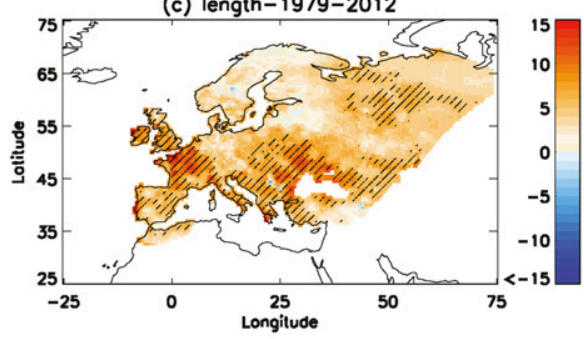

(f) onset-1979-2012

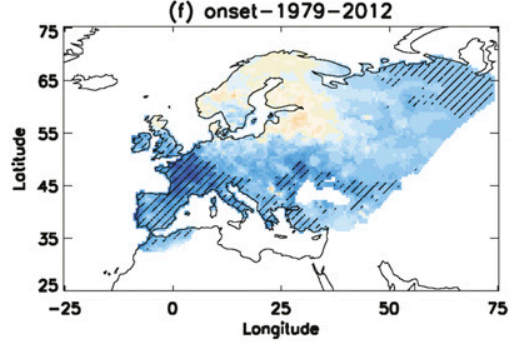

(i) end-1979-2012



FIG. 3. Linear trends over Europe of the summer length (days decade ${ }^{-1}$ ) for (a) 1950-2012, (b) 1950-78, and (c) 1979-2012. (d)-(f) As in (a)-(c), but for the summer onset dates (days decade ${ }^{-1}$ ). (g)-(i) As in (a)-(c), but for the summer end dates (days decade ${ }^{-1}$ ). Striped areas show significant trends at the $95 \%$ confidence level.

(more) persisting summers before (after) the late 1970s. A more detailed analysis based on the calculation of trends for two running subperiods through the 19502012 interval identifies 1979 as a turning point. In other words, this year marks the transition from a period of declining trends toward a period of increasing trends in the summer length. To better analyze the spatial pattern of these interdecadal variations in the duration of the summer, we have split the full record in two subperiods: $1950-78$ and $1979-2012$. The length of the summer displays significant positive trends for the post-1979 period (Fig. 3c), which range between 5 and 12 days decade $^{-1}$ over some regions of eastern and western Europe and reach a spatially averaged trend for the entire Europe of 6.3 days decade $^{-1}$ (Table 1). On the contrary, the summer shortened during the pre1979 period in most of Europe (Fig. 3b), reaching significant values between -5 and -15 days decade ${ }^{-1}$ over the same regions of eastern Europe that experienced a significant lengthening after 1979. The European trend

TABLE 1. European mean linear trends (days decade ${ }^{-1}$ ) of the summer onset, end, and length for 1950-2012, 1950-78, and 1979-2012. The column headings Actual, AMO, and Global indicate, respectively, the trends derived from the raw data, the values fitted to the AMO, and the values fitted to the global mean temperature. Trends that are statistically significant at the $95 \%$ level are shown in boldface. See text for details.

\begin{tabular}{|c|c|c|c|c|c|c|c|c|c|}
\hline & \multicolumn{3}{|c|}{ 1950-2012 } & \multicolumn{3}{|c|}{$1950-78$} & \multicolumn{3}{|c|}{ 1979-2012 } \\
\hline & Actual & AMO & Global & Actual & AMO & Global & Actual & AMO & Global \\
\hline Onset & -1.4 & -0.5 & -1.8 & 2.8 & 3.4 & -0.3 & -4.1 & -2.0 & -2.5 \\
\hline End & 0.9 & 0.2 & 1.0 & -1.6 & -1.4 & 0.1 & 2.3 & 1.1 & 1.4 \\
\hline Length & 2.4 & 0.9 & 2.7 & -4.5 & -5.2 & 0.4 & 6.3 & 3.7 & 3.8 \\
\hline
\end{tabular}


(a) JUN-1950-1978

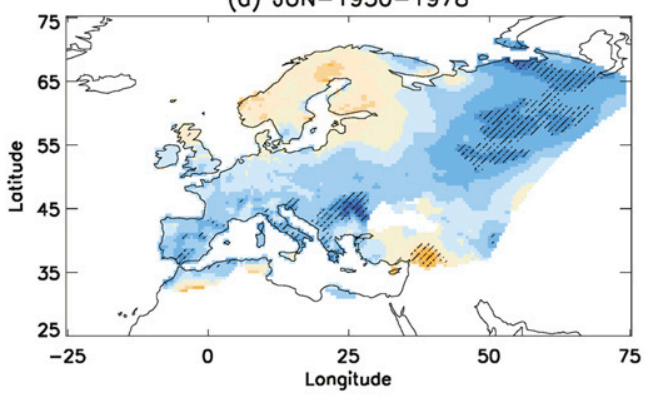

(c) SEP-1950-1978

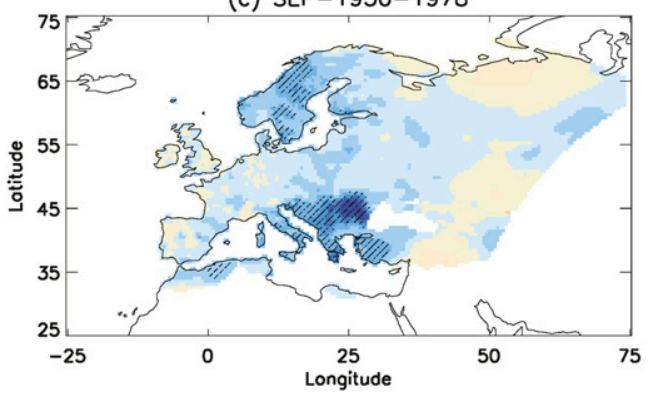

(b) JUN-1979-2012



(d) SEP-1979-2012

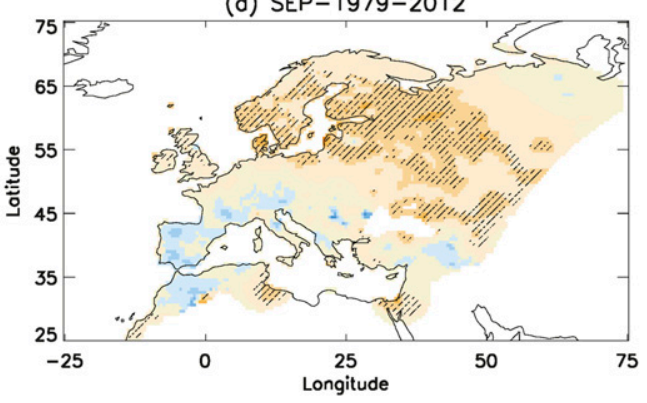

FIG. 4. Linear temperature trends $\left({ }^{\circ} \mathrm{C}\right.$ decade $\left.{ }^{-1}\right)$ of (a),(b) June and (c),(d) September for the (left) pre-1979 and (right) post-1979 periods. Striped areas show significant trends at the $95 \%$ confidence level.

before 1979 was -4.5 days decade $^{-1}$ (Table 1), which means that, on average, the summer shortened over the earlier period less than it lengthened over the more recent interval.

These results for the pre- and post-1979 periods are consistent with the trends detected in the summer onset and end. Thus, Fig. 2e shows an intensification of the summer onset trends after 1979, with a European average value of -4.1 days decade ${ }^{-1}$ (Table 1 ), and ranging between -5 and -10 days decade ${ }^{-1}$ over western Europe and the Mediterranean countries (Fig. 3f). This trend is equal to a total advance of the summer onset of more than 12 days over these regions for the 34-yr period. No significant changes in the summer onset are detected after 1979 over eastern Europe. However, a later retreat of the summer occurred therein for the post-1979 period, reaching values between 3 and 6 days decade ${ }^{-1}$ and a European-wide average rate of 2.3 days decade $^{-1}$ (Table 1 ), thus explaining the summer lengthening over these regions.

Trends in the summer onset and end for the pre-1979 period are opposite in sign to those found for the post1979 period, but they are also weaker (see Figs. 2e,f). Thus, the overall trend pattern of the summer length for the 1950-2012 period results from the superposition of two effects: a significantly earlier summer onset in western Europe and a significant autumn delay in eastern Europe. These regions experienced the largest trends in the post-1979 period, overwhelming opposite trends during the pre-1979 period. Similar conclusions are obtained for the NNR and the HadGHCND data products, as can be seen in Figs. S3 and S4 of the supplementary material.

\section{b. Summer timing changes and temperature}

The reported trends in the summer timing and length should be related to temperature changes over the onset and end periods. Thus, we have analyzed the temperature trends of June and September. The June temperature trends after 1979 (Fig. 4b) show a widespread warming except over Scandinavia and western Russia, which is in good agreement with the trends found for the onset date (Fig. 3f). The warming trend reaches maximum and significant values between $0.5^{\circ}$ and $1.2^{\circ} \mathrm{Cdecade}^{-1}$ over western and central Europe and the Mediterranean region, the areas where the summer onset trends have been more pronounced. On the contrary, for the pre-1979 period, a weak but widespread cooling is observed (Fig. 4a) except, again, in Scandinavia. The temperature trend reaches significant values below $-0.5^{\circ} \mathrm{Cdecade}^{-1}$ only over Russia and scattered areas of the Mediterranean region. As expected, the most intense cooling is observed over those regions with a faster delay of the summer onset for the pre-1979 period (Fig. 3e). 
Temperature trends in September show warming over eastern Europe of around $0.5^{\circ}$ and $0.75^{\circ} \mathrm{C}$ decade $^{-1}$ after 1979 (Fig. 4d), which explains the late retreat of the summer observed over this region in Fig. 3i. On the other hand, as for June, the September temperatures experienced a widespread cooling before 1979 (Fig. 4c), although they only reached significant values over some parts of Scandinavia and the Balkans (i.e., the same regions with an earlier summer end for the pre-1979 period; Fig. 3h).

These temperature trends are in agreement with results shown in the Fifth Assessment Report of the IPCC (Hartmann et al. 2013). Although this report does not show monthly or seasonal trends, it makes evident that, in annual mean terms, a warming occurred over Europe during 1981-2012 whereas a cooling was observed over extended European regions during 1951-80. This report shows annual mean temperature trends over Europe that oscillate between $0.2^{\circ}$ and $0.5^{\circ} \mathrm{Cdecade}^{-1}$ during 1981-2012. As expected, these trends are slightly lower than those shown here because the observed European temperature trends in recent decades are higher in summer than in any other season (Trenberth et al. 2007).

\section{c. Summer timing multidecadal variability and $A M O$}

Up to now, we have found that the trends in summer timing and length have not been uniform through the 1950-2012 period. As stated in the introduction, the $\mathrm{AMO}$ is as a major factor modulating the European summer climate on multidecadal time scales. Consistently, Fig. $2 d$ shows that the AMO index is significantly correlated with the European summer length at $p<$ 0.05 , reaching a value of 0.53 , as well as with the summer onset date $(r=-0.50, p<0.05$; Fig. 2e). Therefore, one could expect an AMO influence on the aforementioned multidecadal variability of the summer length. In this section, we investigate the role of the AMO in shaping the spatial patterns associated to multidecadal changes in the summer length.

To do so, we first applied a 10-yr moving average to the summer length anomaly series at each grid point in order to retain variability at multidecadal time-scales. Then, a principal component analysis (PCA) of the filtered summer length series was applied. A similar PCA analysis has been applied to the summer onset and end. It should be stressed that the first EOFs of the summer onset, end, and length explain much higher variance $(\sim 50 \%)$ than the higher modes of variability $(<15 \%)$. This indicates that most of the multidecadal variability and trend of the European summer timing is well captured by the leading mode of variability. Thus, we focus on the first empirical orthogonal function (EOF1), unless higher modes of variability are significantly associated with the AMO. On the other hand, to quantify the AMO influence on the summer timing and length, we have performed a correlation analysis between the AMO and the corresponding PC, in which the reduction of degrees of freedom due to serial autocorrelation is taken into account, as described in section 2.

Figures $5 \mathrm{a}$ and $5 \mathrm{~b}$ show the EOF1 obtained for the summer length, with positive (negative) loadings denoting a lengthening (shortening) of the summer, and its associated principal component (PC1) time series. EOF1 explains $58 \%$ of the total variance and resembles the spatial pattern of the summer length trends depicted in Fig. 3a, with a generalized summer lengthening, except in some regions of Scandinavia. PC1 displays a declining trend until 1979, increasing afterward, capturing the characteristic trends of the summer length found in Figs. 2d and 3b,c. Thus, EOF1 and PC1 mainly reflect the spatial pattern and the multidecadal evolution associated with the summer length. We compared the PC1 time series with the 10-yr smoothed AMO index averaged for June and September (Fig. 5b). The correlation reaches a significant $(p<0.05)$ value of 0.85 , suggesting that the AMO is relevant in modulating the summer length.

The strong relationship between the summer length and the AMO is consistent with the fact that trends in the summer length are largely a consequence of the observed changes in the summer onset, which in turn is also highly correlated with the AMO. This is seen in Figs. $5 \mathrm{c}$ and $5 \mathrm{~d}$, which depict EOF1 and PC1 of the summer onset date (accounting for $46 \%$ of the total variance). This EOF1 shows a rather uniform behavior across Europe except for Scandinavia, and resembles the spatial pattern of trends in the summer onset depicted in Fig. 3d. The main feature of the associated PC1 (Fig. 5d) is the existence of trends that change their sign along the second half of the 1970s. Thus, PC1 accurately captures the opposite trends that characterized the behavior of the summer onset in Europe during the preand post-1979 periods (Fig. 5e). This PC1 is significantly correlated $(r=0.90, p<0.05)$ with the smoothed AMO index for June (i.e., the month when the summer onset occurs).

Regarding the changes in the summer end date, it is found that the first mode of variability ( $54 \%$ of total variance; Fig. 5e) captures well the observed trend in the summer end after 1979 (Fig. 3i), while the second mode (14\% of total variance; Fig. 5f) does so for the pre-1979 period (Fig. 3h). Both PC1 and PC2 are significantly correlated with the smoothed AMO index of September, although the correlation coefficients $(r=0.7, p<$ 0.05 and $r=0.46, p<0.05$, respectively) are lower than those obtained for the summer onset. However, the sum 
(a) length

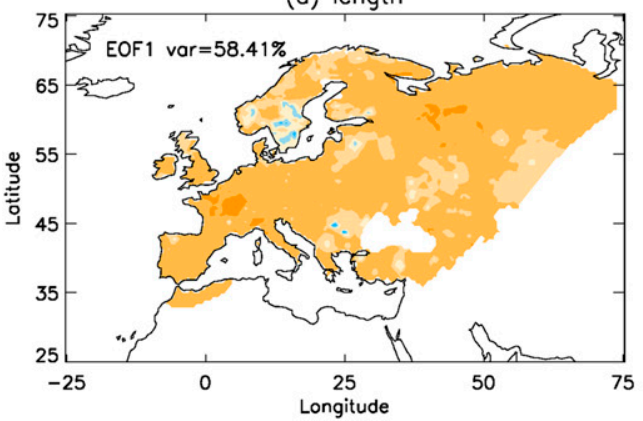

(c) onset



(e) end

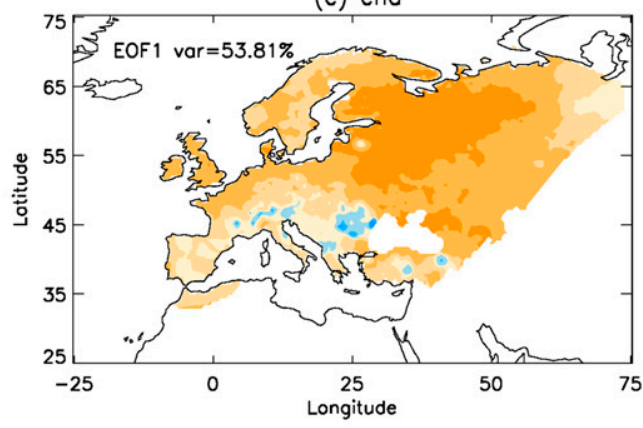

(f) end

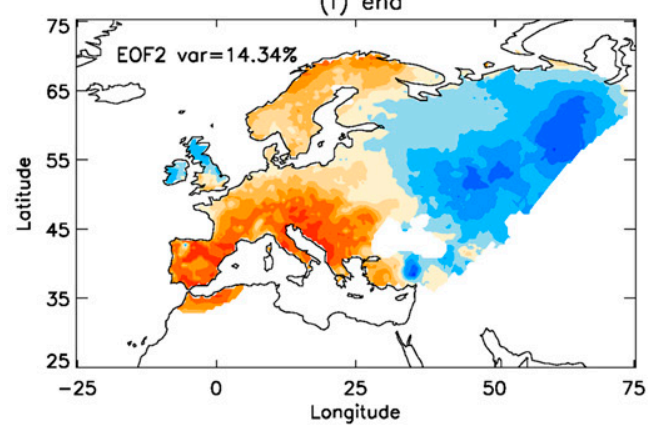



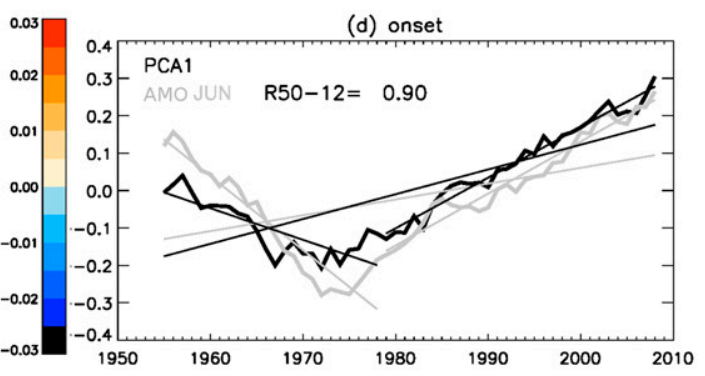

FIG. 5. EOFs and their corresponding PCs of the 10-yr smoothed time series of (a),(b) summer length, (c),(d) summer onset, and (e)-(g) summer end. Red (blue)-shaded areas in the EOF patterns indicate positive (negative) loadings (in relative units), and represent a lengthening (shortening) of the summer length and later (earlier) onset and end dates, respectively. The explained variance by the corresponding PC is shown in the top-left corner of (a),(c),(e), and (f). In (b),(d), and (g), black and gray lines represent the standardized series of the corresponding PCs and the 10-yr smoothed AMO index, respectively. In (g), dashed and dotted lines represent PC1 and PC2, respectively, whereas PC1 + PC2 is shown with a solid line. The R50-12 value represents the correlation coefficient of the corresponding PC and the AMO index. We only show those PCs that are significantly correlated with the smoothed AMO index at the $95 \%$ confidence level. See text for details. 
(o) length-1950-2012

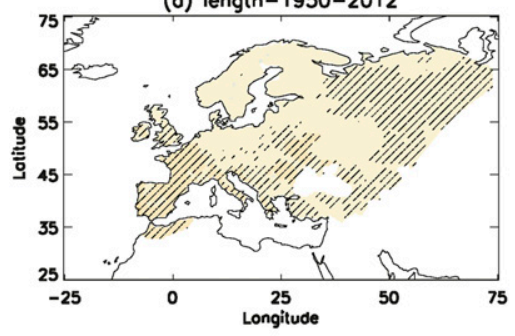

(d) onset-1950-2012

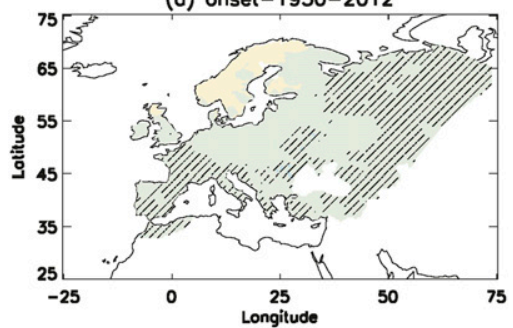

(g) end-1950-2012

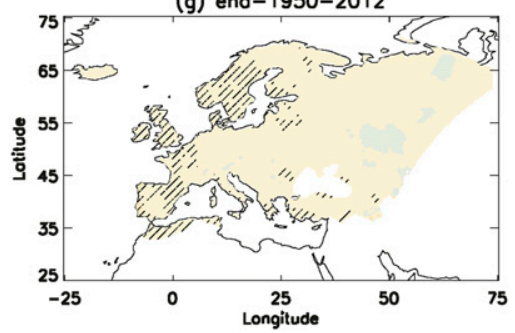

(b) length-1950-1978

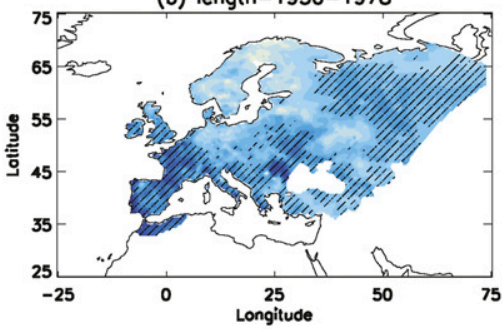

(e) onset-1950-1978



(h) end-1950-1978



(c) length-1979-2012

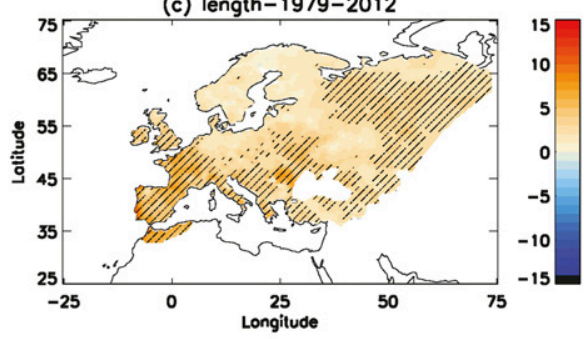

(f) onset-1979-2012

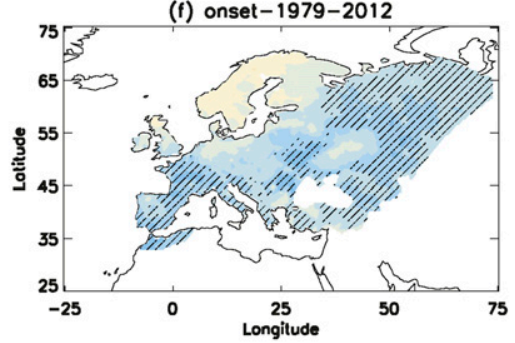

(i) end-1979-2012

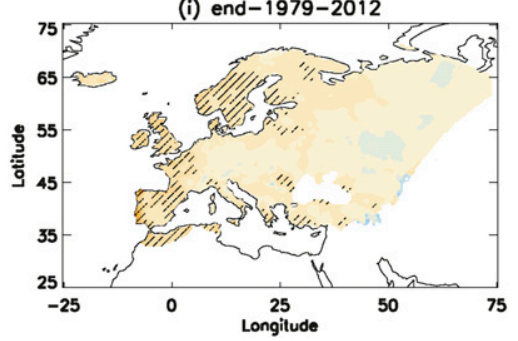

FIG. 6. As in Fig. 3, but for the (a)-(c) summer length, (d)-(f) summer onset, and (g)-(i) summer end trends derived from a linear model that depends, repectively, on the June and September mean, the June AMO index, and the September AMO index. Striped areas show where the linear fit to the AMO index is significant at the $95 \%$ confidence level.

of PC1 and PC2 has a correlation coefficient of $0.82(p<$ $0.05)$ with the smoothed AMO index for September (Fig. 5g). This suggests that the AMO has also a noticeable influence on the multidecadal variability of the summer end.

\section{d. Discussion}

To quantify the trends in the summer timing and length that are linearly associated with the AMO, we performed a linear regression analysis to express summer onset, end, and length as a function of the AMO index:

$$
y=\beta_{0}+\beta_{0} x,
$$

where $y$ represents the fitted values of summer onset, end, or length and $x$ is the AMO index for June, September, or the June and September mean, respectively. In a second step, we computed the linear trends of the fitted values $y$ for the pre- and post-1979 intervals as well as for the period 1950-2012 (Fig. 6). These trends correspond to the linear variation of the summer timing and length explained by the AMO and reveal a lengthening (shortening) of the summer over the periods dominated by a positive (negative) trend of the AMO index (cf. Figs. 6 and 2d-f). As a consequence, there is a turning point in the estimated trends of the summer, which is coincident with the AMO shift toward more positive values in the late 1970s.

A comparison of Figs. 3 and 6 evidences the similarity between the spatial patterns of the trends obtained from the raw data (Fig. 3) and from the fitted values (Fig. 6), suggesting that the AMO has contributed in a noticeable manner to the trends observed over the last decades. However, despite the qualitative agreement between the trends obtained from the raw and fitted values, their magnitudes are remarkably different. This indicates that other factors are contributing to the trends in the summer length.

As shown in section $3 \mathrm{~b}$, the trends in the summer onset, end, and length are in good agreement with the long-term temperature trends of June, September, and 
the June and September mean. To better quantify the global warming effect on the actual summer trends we have a performed a linear regression analysis of the summer onset, end, and length with the global mean temperature from the HadCRUT3v_GL dataset. As in the case of the AMO, the regression is based on (1), but with $x$ being the global mean temperature. In this way, we are able to compare the relative contributions of the $\mathrm{AMO}$ and the global warming to the observed trends of the summer onset, end, and length. Note that the AMO and the global temperature series are not fully independent. However, the AMO index is obtained after detrending SSTs over the North Atlantic, with the aim of removing the climate change signal. Table 1 summarizes the European mean trends in the summer length, onset, and end dates for the full period and the pre- and post1979 periods, as inferred from the raw data and the data fitted to the AMO and to the global temperature. After 1979, the lengthening was almost twice what could be expected from a linear AMO impact, whereas prior to this date the observed shortening was lower than that associated with the AMO. These quantitative discrepancies can be explained by a warming trend that partially compensates the cooling and the consequent shortening of the summer linked to the AMO prior to 1979 and, on the contrary, enhances the warming and its subsequent summer lengthening related to the AMO after 1979. This is confirmed by the trends expected from global warming, which work to offset the trends due to the AMO before 1979 and to increase them thereafter. In fact, the sum of the linear trends that can be attributed to the AMO and global warming is in better agreement with the actual trend than those obtained separately from either the AMO or the global warming alone. It is also important to notice that the trends associated with the AMO are generally stronger for the pre-1979 period, which is consistent with a more pronounced trend of the AMO index over this time interval (Fig. 2d). Similarly, the trends derived from the global warming always lead to an earlier (later) summer onset (end) and to a summer lengthening, but they were much smaller before than after 1979, in agreement with an acceleration rate of the global warming (Hartmann et al. 2013).

The changes found for the summer onset and end dates are consistent with the trends in the summer length. Thus, the European mean delay (advance) of the summer onset (end) prior to 1979 associated with the AMO was larger than the observed changes for the same period, in accordance with an offsetting effect of the global warming. On the contrary, the summer onset advance and the end delay observed during the full period and after 1979 occurred faster than the AMO can explain. In fact, the observed trends in the onset and end almost double those explained by the AMO after 1979. This is in agreement with global warming accounting for about half or more of the actual trends. Note also that the trends due to the AMO and global warming are larger for the summer onset than for the summer end dates. This agrees with the results in section 3 , according to which the AMO exerts a larger influence on the summer onset than on the summer end (Figs. 5 and 6), and there are larger trends in June (onset) than in September (end) summer temperatures (Figs. 2 and 4).

Again, the discrepancies between the observed and AMO-related trends peak for the period 1950-2012, when the multidecadal modulation of the AMO is filtered out, and the resulting weak trend in the AMO index (Figs. 2d-f) only accounts for about one-third of the observed trends. As a consequence, the 1950-2012 trends are strongly associated with global warming. However, on multidecadal time scales, which are important for decadal predictions, the AMO plays an important role in accelerating or damping the trends that could be expected from global change.

The results found herein suggest a multidecadal modulation of the European summer length by the AMO. This is in good agreement with previous studies reporting some influence of the AMO on the decadal variability of European summer temperatures (e.g., Sutton and Hodson 2005) and European heat waves (e.g., Della-Marta et al. 2007b). However, the specific mechanisms whereby the AMO modulates the European summer temperatures are not fully understood. Because of the large-scale and slowly varying nature of the AMO, a warm state of the North Atlantic Ocean could cause positive temperature anomalies over Europe by warming the atmospheric layer aloft and advecting the air over land (Sutton and Dong 2012). In fact, positive AMO phases are associated with tropospheric mean $(200-600 \mathrm{hPa})$ warming over large areas of the northern Atlantic and Eurasia (Goswami et al. 2006).

However, there is a seasonal dependence of the AMO climate impacts on Europe (e.g., Knight et al. 2006; Mariotti and Dell'Aquila 2012), which suggests some contributing role of atmospheric dynamics. Thus, Sutton and Dong (2012) found that positive AMO phases are associated with warm anomalies over western and southern Europe during spring and summer, respectively, whereas in autumn the largest warming occurs in northern Europe, near Scandinavia. These contrasting seasonal patterns resemble, respectively, those found herein for the post-1979 trends in the summer onset (Fig. 3f) and end (Fig. 3i).

Some of the atmospheric circulation changes associated with the AMO include the frequency of eastern 
Atlantic blocking during winter (e.g., Häkkinen et al. 2011) and a multidecadal modulation of the highsummer (July-August) North Atlantic Oscillation (SNAO; e.g., Folland et al. 2009) and the North Atlantic summer storm tracks (Dong et al. 2013). There is indication that some of the summer atmospheric changes may be a downstream response to extratropical SST anomalies (Sutton and Hodson 2005), although subtropical Atlantic SSTs may also play a role, as they do in the occurrence of heat wave-related circulation patterns over Europe (e.g., Cassou et al. 2005). Further research is required to explore the atmospheric circulation patterns associated with the AMO during transitional months (June and September), which are critical for the summer onset and end. In addition, modeling studies would help to better quantify the AMO influence on the European summer length and to explore other potential factors affecting the multidecadal variability of the summer.

\section{Conclusions}

Our results show evidence of a European mean summer lengthening of 2.4 days decade ${ }^{-1}$ for the 1950-2012 period, with the change confined to the post-1979 period. Therefore, the lengthening of the European summer has occurred at a faster rate over the last three decades, doubling previous estimates obtained for the second half of the twentieth century (e.g., Klein Tank and Können 2003) and climbing to an average value of 6.3 days decade $^{-1}$ for the 1979-2012 period.

The summer lengthening after 1979 is not homogeneous and reaches maximum values between 5 and 12 days decade $^{-1}$ over most of western Europe and the Mediterranean region. Conversely, the pre-1979 period was marked by a shortening of the summer that mostly affected southern Europe, but it was on average 30\% weaker than the post-1979 lengthening. This variability is mainly attributable to a delay (advance) of the summer onset over the pre-1979 (post 1979) period and, to a lesser extent, to the advance (delay) of the summer end over the same intervals, since the trends in the end dates have been generally weaker than those of the onset. We note some regional inconsistencies between different datasets that point to data quality issues in the E-OBS dataset. However, they are mostly confined to some regions of the Balkans and eastern Turkey, and they do not affect the main conclusions of this paper. In particular, the European mean estimates of trends and multidecadal variability of the summer onset, end, and length are robust across the three different datasets explored.

The lengthening of the summer after 1979 is related to a significant rise of June temperatures of approximately 0.5 $1.2^{\circ} \mathrm{Cdecade}^{-1}$ over western and southern Europe and, secondarily, to a temperature increase of September temperatures in the range of $0.5^{\circ}-0.75^{\circ} \mathrm{Cdecade}^{-1}$ over eastern Europe. On the other hand, the pre-1979 shortening is linked to a cooling trend in June and September that is generally weaker than the post-1979 warming, except over Russia and the Balkans, and some parts of the Scandinavian Peninsula, respectively.

Our results indicate that trends in the European mean summer timing and length for the full 1950-2012 period are in good agreement with those expected by global warming. However, we find substantial multidecadal variability of the summer length over the last decades, and report a shift around 1979 in the temporal evolution of the summer trends, with a change from a summer shortening to a summer lengthening by that time. This is partially linked to the AMO, which shows a similar evolution, with a turning point in the late 1970s. The negative trend of the AMO prior to 1979 has contributed to a later summer onset and to an earlier summer end over large areas of Europe, thus resulting in a shortening of the summer season. Conversely, the shift to a positive AMO trend after 1979 contributed to an earlier summer onset and a later summer end, giving rise to a summer lengthening. However, the magnitude of the summer timing changes observed for these periods cannot be fully explained by changes in the AMO. Thus, the summer shortening before 1979 has been slightly smaller than that expected from the AMO, whereas the observed summer lengthening after 1979 has been almost 2 times faster. These results are compatible with a superimposed warming leading to a summer lengthening along the full period. This long-term trend is large enough to counteract the AMO-related changes prior to 1979 , causing a weaker shortening of the summer, and to accelerate the summer lengthening linked to the AMO after 1979.

Acknowledgments. This work has been partly supported by the research project CGL2014-51721-REDT funded by the Spanish Ministry of Economy and Competitiveness and by Iberdrola Renovables under Contract 4502746576. We acknowledge the E-OBS dataset from the EU-FP6 project ENSEMBLES (http:// ensembles-eu.metoffice.com), including the data providers in the ECA\&D project (http://www.ecad.eu), the Met Office in collaboration with the National Climatic Data Center of NOAA, the Climatic Research Unit (University of East Anglia) in conjunction with the Hadley Centre, and the NCEP-NCAR reanalysis project at the Physical Sciences Division of NOAA/ESRL for providing the data. We also thank the editor and two anonymous reviewers for their helpful comments on this manuscript. 


\section{REFERENCES}

Barriopedro, D., E. M. Fischer, J. Luterbacher, R. M. Trigo, and R. García-Herrera, 2011: The hot summer of 2010: Redrawing the temperature record map of Europe. Science, 332, 220-224, doi:10.1126/science.1201224.

Caesar, J., L. Alexander, and R. Vose, 2006: Large-scale changes in observed daily maximum and minimum temperatures: Creation and analysis of a new gridded data set. J. Geophys. Res., 111, D05101, doi:10.1029/2005JD006280.

Cassou, C., L. Terray, and A. S. Phillips, 2005: Tropical Atlantic influence on European heat waves. J. Climate, 18, 2805-2811, doi:10.1175/JCLI3506.1.

Cayan, D. R., M. D. Dettinger, S. A. Kammerdiener, J. M. Caprio, and D. H. Peterson, 2001: Changes in the onset of spring in the western United States. Bull. Amer. Meteor. Soc., 82, 399-415, doi:10.1175/1520-0477(2001)082<0399: CITOOS $>2.3 . \mathrm{CO} ; 2$.

Chmielewski, F.-M., A. Müller, and E. Bruns, 2004: Climate changes and trends in phenology of fruit trees and field crops in Germany, 1961-2000. Agric. For. Meteor., 121, 69-78, doi:10.1016/S0168-1923(03)00161-8.

Christensen, J. H., and Coauthors, 2013: Climate phenomena and their relevance for future regional climate change. Climate Change 2013: The Physical Science Basis, T. F. Stocker et al., Eds., Cambridge University Press, 12171308.

Christidis, N., P. A. Stott, S. Brown, D. J. Karoly, and J. Caesar, 2007: Human contribution to the lengthening of the growing season during 1950-99. J. Climate, 20, 5441-5454, doi:10.1175/ 2007JCLI1568.1.

Cotton, P. A., 2003: Avian migration phenology and global climate change. Proc. Natl. Acad. Sci. USA, 100, 12219-12222, doi:10.1073/pnas.1930548100.

Della-Marta, P. M., M. R. Haylock, J. Luterbacher, and H. Wanner, 2007a: Doubled length of western European summer heat waves since 1880. J. Geophys. Res., 112, D15103, doi:10.1029/2007JD008510.

_ - J. Luterbacher, H. von Weissenfluh, E. Xoplaki, M. Brunet, and H. Wanner, 2007b: Summer heat waves over western Europe 1880-2003, their relationship to large-scale forcings and predictability. Climate Dyn., 29, 251-275, doi:10.1007/ s00382-007-0233-1.

D'Ippoliti, D., and Coauthors, 2010: The impact of heat waves on mortality in 9 European cities: Results from the EuroHEAT project. Environ. Health, 9, 37, doi:10.1186/ 1476-069X-9-37.

Dong, B., R. T. Sutton, T. Woollings, and K. Hodges, 2013: Variability of the North Atlantic summer storm track: Mechanisms and impacts on European climate. Environ. Res. Lett., 8, 034037, doi:10.1088/1748-9326/8/3/034037.

Enfield, D. B., A. M. Mestas-Nuñez, and P. J. Trimble, 2001: The Atlantic multidecadal oscillation and its relationship to rainfall and river flows in the continental U.S. Geophys. Res. Lett., 28, 2077-2080, doi:10.1029/2000GL012745.

Folland, C., J. Knight, H. Linderholm, D. Fereday, S. Ineson, and J. W. Hurrell, 2009: The summer North Atlantic Oscillation: Past, present, and future. J. Climate, 22, 1082-1103, doi:10.1175/2008JCLI2459.1.

García-Herrera, R., J. Díaz, R. M. Trigo, J. Luterbacher, and E. M. Fischer, 2010: A review of the European summer heat wave of 2003. Crit. Rev. Environ. Sci. Technol., 40, 267-306, doi:10.1080/10643380802238137.
Goswami, B. N., M. S. Madhusoodanan, C. P. Neema, and D. Sengupta, 2006: A physical mechanism for North Atlantic SST influence on the Indian summer monsoon. Geophys. Res. Lett., 33, L02706, doi:10.1029/ 2005GL024803.

Häkkinen, S., P. B. Rhines, and D. L. Worthen, 2011: Atmospheric blocking and Atlantic multidecadal ocean variability. Science, 334, 655-659, doi:10.1126/ science.1205683.

Hartmann, D. L., and Coauthors, 2013: Observations: Atmosphere and surface. Climate Change 2013: The Physical Science Basis, T. F. Stocker et al., Eds., Cambridge University Press, 159254.

Haylock, M. R., N. Hofstra, A. M. G. Klein Tank, E. J. Klok, P. D. Jones, and M. New, 2008: A European daily highresolution gridded data set of surface temperature and precipitation. J. Geophys. Res., 113, D20119, doi:10.1029/ 2008JD010201.

Hofstra, N., M. Haylock, M. New, and P. D. Jones, 2009: Testing E-OBS European high-resolution gridded data set of daily precipitation and surface temperature. J. Geophys. Res., 114, D21101, doi:10.1029/2009JD011799.

Kalnay, E., and Coauthors, 1996: The NCEP/NCAR 40-Year Reanalysis Project. Bull. Amer. Meteor. Soc., 77, 437-471, doi:10.1175/1520-0477(1996)077<0437: TNYRP $>2.0 . \mathrm{CO} ; 2$.

Kirbyshire, A. L., and G. R. Bigg, 2010: Is the onset of the English summer advancing? Climatic Change, 100, 419-431, doi:10.1007/s10584-010-9843-4.

Klein Tank, A. M. G., and G. P. Können, 2003: Trends in indices of daily temperature and precipitation extremes in Europe, 1946-99. J. Climate, 16, 3665-3680, doi:10.1175/ 1520-0442(2003)016<3665:TIIODT $>2.0$. CO 2 .

Knight, J. R., C. K. Folland, and A. A. Scaife, 2006: Climate impacts of the Atlantic multidecadal oscillation. Geophys. Res. Lett., 33, L17706, doi:10.1029/2006GL026242.

Kyselý, J., and E. Plavcová, 2010: A critical remark on the applicability of E-OBS European gridded temperature data set for validating control climate simulations. J. Geophys. Res., 115, D23118, doi:10.1029/2010JD014123.

López de la Franca, N., E. Sánchez, and M. Domínguez, 2013: Changes in the onset and length of seasons from an ensemble of regional climate models over Spain for future climate conditions. Theor. Appl. Climatol., 114, 635-642, doi:10.1007/ s00704-013-0868-2.

Mariotti, A., and A. Dell'Aquila, 2012: Decadal climate variability in the Mediterranean region: Roles of large-scale forcings and regional processes. Climate Dyn., 38, 1129-1145, doi:10.1007/ s00382-011-1056-7.

Matsumoto, K., T. Ohta, M. Irasawa, and T. Nakamura, 2003: Climate change and extension of the Ginkgo biloba L. growing season in Japan. Global Change Biol., 9, 1634-1642, doi:10.1046/j.1365-2486.2003.00688.x.

Menzel, A., and Coauthors, 2006: European phenological response to climate change matches the warming pattern. Global Change Biol., 12, 1969-1976, doi:10.1111/ j.1365-2486.2006.01193.x.

Oort, A. H., and J. J. Yienger, 1996: Observed interannual variability in the Hadley circulation and its connection to ENSO. J. Climate, 9, 2751-2767, doi:10.1175/ 1520-0442(1996)009<2751:OIVITH $>2.0 . \mathrm{CO} ; 2$.

Robine, J.-M., S. L. K. Cheung, S. Le Roy, H. Van Oyen, C. Griffiths, J.-P. Michel, and F. R. Herrmann, 2008: Death toll 
exceeded 70,000 in Europe during the summer of 2003. C. R. Biol., 331, 171-178, doi:10.1016/j.crvi.2007.12.001.

Schwartz, M. D., R. Ahas, and A. Aasa, 2006: Onset of spring starting earlier across the Northern Hemisphere. Global Change Biol., 12, 343-351, doi:10.1111/ j.1365-2486.2005.01097.x.

Sparks, T., and A. Menzel, 2002: Observed changes in seasons: An overview. Int. J. Climatol., 22, 1715-1725, doi:10.1002/joc.821.

Stine, A., P. Huybers, and I. Fung, 2009: Changes in the phase of the annual cycle of surface temperature. Nature, 457, 435-440, doi:10.1038/nature07675.
Sutton, R. T., and D. L. R. Hodson, 2005: Atlantic Ocean forcing of North American and European summer climate. Science, 309, 115-118, doi:10.1126/science.1109496.

- and B. Dong, 2012: Atlantic Ocean influence on a shift in European climate in the 1990s. Nat. Geosci., 5, 788-792, doi:10.1038/ngeo1595.

Trenberth, K. E., and Coauthors, 2007: Observations: Surface and atmospheric climate change. Climate Change 2007: The Physical Science Basis, S. Solomon et al., Eds., Cambridge University Press, 235-336. [Available online at http://www.ipcc.ch/pdf/ assessment-report/ar4/wg1/ar4-wg1-chapter3.pdf.] 